\title{
Self-Esteem and Achievement Motivation among Female NCC Cadets and Non-NCC Cadets
}

\author{
N.V. Amudha Devi ${ }^{1}$, Sruthi Suresh ${ }^{2}$ \\ ${ }^{1}$ Assistant Professor, Department of Psychology, Avinashilingam Institute for Home Science and Higher Education \\ for Women, Coimbatore. \\ ${ }^{2}$ Post graduate student, Department of Psychology, Avinashilingam Institute for Home Science and Higher Education \\ for Women, Coimbatore. \\ E-mail - amudhadevikrishnan@gmail.com
}

\begin{abstract}
Background: Motivation can be defined as the driving force behind all the actions of an individual. Achievement motivation is based on reaching success and achieving all of our aspirations in life. And, selfesteem is often seen as a personality trait, which means that it tends to be stable and enduring. The influence of an individual's needs and desires both have a strong impact on the direction of their behavior. Achievement Motivation and Self Esteem are significant in day to day activities and also in career. If an individual is high in these two traits he/she will be able to make use of the abundant opportunities available and can succeed. Therefore, it is necessary to understand the factors that will help to improve achievement motivation and self esteem in an individual. This study is aimed to assess the self-esteem and achievement motivation among female NCC cadets and non-NCC cadets.

Methodology: The sample of the study consisted of 50 NCC cadets and 50 non-NCC cadets from various colleges of Coimbatore in Tamil Nadu. The Achievement Motivation Test by Bhargava and the Self Esteem Scale by Rosenberg were used to collect the data.

Results: It was found that the NCC cadets were as a group slightly more achievement motivated than the non-NCC cadets and the self-esteem was slightly higher for non-NCC cadets than the NCC cadets, but there were no significant differences.

Conclusion: This is an area that needs further research and exploration and NCC cadets across various colleges need to be studied to further validate the findings of this study.
\end{abstract}

Key Words: Self-Esteem, Achievement Motivation, Female, NCC cadets, cadets

(Paper received $-3^{\text {rd }}$ April 2017, Peer review completed $-14^{\text {th }}$ April 2017, Accepted $-18^{\text {th }}$ April 2017)

\section{INTRODUCTION}

\section{Achievement Motivation}

Motivation can be defined as the driving force behind all the actions of an individual. The influence of an individual's needs and desires both have a strong impact on the direction of their behaviour. Motivation is based on your emotions and achievement-related goals. There are different forms of motivation including extrinsic, intrinsic, physiological, and achievement motivation. There are also more negative forms of motivation. Achievement motivation can be defined as the need for success or the attainment of excellence. Individuals will satisfy their needs through different means, and are driven to succeed for varying reasons both internal and external [1-2]. 
Achievement motivation is based on reaching success and achieving all of our aspirations in life. Achievement goals can affect the way a person performs a task and represent a desire to show competence [3]. These basic physiological motivational drives affect our natural behavior in different environments. Most of our goals are incentive-based and can vary from basic hunger to the need for love and the establishment of mature sexual relationships. Our motives for achievement can range from biological needs to satisfying creative desires or realizing success in competitive ventures. Achievement motivation has been conceptualized in many different ways. Our understanding of achievement-relevant effects, cognition, and behavior has improved. Despite being similar in nature, many achievement motivation approaches have been developed separately, suggesting that most achievement motivation theories are in concordance with one another instead of competing. Motivational researchers have sought to promote a hierarchal model of approach and avoidance achievement motivation by incorporating the two prominent theories: the achievement motive approach and the achievement goal approach. Achievement motives include the need for achievement and the fear of failure. These are the more predominant motives that direct our behavior toward positive and negative outcomes [4].

Achievement goals are viewed as more solid cognitive representations pointing individuals toward a specific end. There are three types of these achievement goals: a performance-approach goal, a performance-avoidance goal, and a mastery goal. A performance-approach goal is focused on attaining competence relative to others, a performance-avoidance goal is focused on avoiding incompetence relative to others, and a mastery goal is focused on the development of competence itself and task mastery. Achievement motives can be seen as direct predictors of achievement-relevant circumstances. Thus, achievement motives are said to have an indirect or distal influence, and achievement goals are said to have a direct or proximal influence on achievement-relevant outcomes [5].

These motives and goals are viewed as working together to regulate achievement behavior. The hierarchal model presents achievement goals as predictors for performance outcomes. The model is being further conceptualized to include more approaches to achievement motivation. One weakness of the model is that it does not provide an account of the processes responsible for the link between achievement goals and performance. As this model is enhanced, it becomes more useful in predicting the outcomes of achievement-based behaviors [5].

Motivational researchers share the view that achievement behavior is an interaction between situational variables and the individual subject's motivation to achieve. Two motives are directly involved in the prediction of behavior, implicit and explicit. Implicit motives are spontaneous impulses to act, also known as task performances, and are aroused through incentives inherent to the task. Explicit motives are expressed through deliberate choices and more often stimulated for extrinsic reasons. Also, individuals with strong implicit needs to achieve goals set higher internal standards, whereas others tend to adhere to the societal norms. These two motives often work together to determine the behavior of the individual in direction and passion [6].

\section{Explicit and Implicit Motives}

Explicit and implicit motivations have a compelling impact on behavior. Task behaviours are accelerated in the face of a challenge through implicit motivation, making performing a task in the most effective manner the primary goal. A person with a strong implicit drive will feel pleasure from achieving a goal in the most efficient way. The increase in effort and overcoming the challenge by mastering the task satisfies the individual. However, the explicit motives are built around a person's self-image [7]. This type of motivation shapes a person's behavior based on their own self-view and can influence their choices and responses from outside cues. The primary agent for this type of motivation is perception or perceived ability. Many theorists still cannot agree whether achievement is based on mastering one's skills or striving to promote a better self-image. Most research is still unable to determine whether these different types of motivation would result in different behaviors in the same environment [8].

\section{Need for Achievement Motivation}

The need for achievement is greatest for those individuals who have a strong desire to excel. Achievers seek neither power nor approval; rather, their only focus is on success. Achievers prefer work that has a 
moderate chance for success (about 50/50) and tend to avoid situations that are low-risk and those that are high-risk. Low-risk situations are avoided because of the presumed ease of accomplishment related to lowrisk activities and the belief that things which come easy are not a true measure of success. High-risk situations are avoided by achievers because of the fear that success might be more related to luck than actual effort. Achievers need to be able to see the correlation between the level of effort they exert and the success that results [9].

\section{Self Esteem}

In psychology, the term self-esteem is used to describe a person's overall sense of self-worth or personal value. Self-esteem is often seen as a personality trait, which means that it tends to be stable and enduring. Self-esteem can involve a variety of beliefs about the self, such as the appraisal of one's own appearance, beliefs, emotions, and behaviors. Self-esteem is how we value ourselves; it is how we perceive our value to the world and how valuable we think we are to others. Self-esteem affects our trust in others, our relationships, our work - nearly every part of our lives [10].

This concept of self-esteem is founded on the premise that it is strongly connected to a sense of competence and worthiness and the relationship between the two as one lives life. The worthiness component of selfesteem is often misunderstood as simply feeling good about oneself, when it actually is tied to whether or not a person lives up to certain fundamental human values, such as finding meanings that foster human growth and making commitments to them in a way that leads to a sense of integrity and satisfaction. A sense of competence is having the conviction that one is generally capable of producing desired results, having confidence in the efficacy of our mind and our ability to think, as well as to make appropriate choices and decisions. Worthiness might be considered the psychological aspect of self-esteem, while competence might be considered the behavioral or sociological aspect of self-esteem. Self-esteem stems from the experience of living consciously and might be viewed as a person's overall judgment of himself or herself pertaining to self-competence and self-worth based on reality [11-12].

Veena and Shastri [13] have investigated whether achievement motivation differed on individual variables (disciplines/courses, academic performance and gender). A questionnaire was administered to 656 pure science and applied science under graduate students from Bangalore city. Academic achievement referred to their results in the previous semester. Gender was also considered for the analysis. The tool used for the present study was Deo-Mohan Achievement Motivation scale (n-Ach). The results indicate a statistically significant difference in achievement motivation among pure science $(\mathrm{N}=317)$ and applied science $(\mathrm{N}=339)$ course students, the achievement motivation does not differ significantly between high $(\mathrm{N}=248)$, and low $(\mathrm{N}=141)$ academic performance students and there is a significant difference in achievement motivation among boys $(\mathrm{N}=305)$ and girls $(\mathrm{N}=351)$.

Heydari, Madani and Rostami studied the relationship between achievement motive, innovation, ambiguity tolerance, self- efficacy, self esteem and self-actualization with entrepreneurship orientation in the students of Azad Islamic University of Khomein. The sample of this study includes 400 BA students of Khomein Azad Islamic University in the years 2009-2010 which were chosen according to the clustering sampling. To collect the data, entrepreneurship orientation test, achievement motive questionnaire, innovation scale, ambiguity tolerance scale, self-efficacy questionnaire, self esteem questionnaire, and self actualization questionnaires were used. The results of Pierson correlation coefficient showed that entrepreneurship orientation has a positive and meaningful relationship with the variables: achievement motive, innovation, self esteem, self efficacy, and se lf- actualization. Self esteem and ambiguity tolerance have a positive and meaningful relationship $(\mathrm{p}<0.01)$. Multi variant regression analysis results showed that the variables of achievement motive, predict self esteem and entrepreneurship innovation in university students [14].

Sekhar and Devi [15] conducted a study that was carried out with the objectives to investigate the gender related differences and differences across academic majors on achievement motivation among college students. The study was carried on 80 undergraduate students of various colleges from Jammu region, 40 males and 40 females (ages 18-23 years) selected by purposive sampling method. As per research plan all 80 subjects were selected on the basis of gender (males and females) and academic majors (arts and 
sciences) using Achievement Motivation Scale. t- Test was used for deriving the results. Significant difference was found between the achievement motivation of sciences and arts stream students and achievement motivation among male and female college students. The differences indicate significant role of gender and academic majors in achievement motivation of college students.

\section{METHODOLOGY}

\section{Sample}

One hundred female NCC cadets and non-NCC cadets of the colleges of Coimbatore were taken for the study. Convenient Sampling method was used to collect the data.

\section{Null Hypothesis}

- The Hypothesis is stated as null hypothesis, so that they can either be accepted or rejected based on results.

- There is no significant correlation between the Self-Esteem and Achievement Motivation among female NCC cadets.

- There is no significant correlation between the Self-Esteem and Achievement Motivation among female non-NCC cadets.

- There is no significant difference in Self-Esteem between female NCC cadets and non-NCC cadets.

- There is no significant difference in Achievement Motivation between female NCC and non-NCC cadets.

\section{Area}

The areas selected to conduct the study were Avinashilingam University, Nirmala College for Women and Government College Technology of Coimbatore. The reasons for selecting these areas were availability of sample and willingness and co-operation of students and faculty.

\section{Tools}

Personal Information Sheet, Self Esteem Scale by Rosenberg [16] and Achievement Motivation Test by Bhargava [17] was used to collect the data.

The Rosenberg's Self Esteem Scale consisted of 10 statements with a four point rating scale and the Achievement Motivation Test consisted of 50 statements, used to assess Self-Esteem and Achievement Motivation.

\section{RESULTS \& DISCUSSION}

Table 1 shows the mean, standard deviation and t-test of Self-Esteem and Achievement Motivation of the female NCC cadets of various colleges. The mean and standard deviation of Self-Esteem is 24.64 and 2.84 respectively, which signifies a very high self-esteem for the group. The mean and standard deviation of Achievement Motivation is 19.42 and 4.72 respectively, which signifies an average achievement motivation for the group as a whole. Table 2 shows the correlation and 'p' value between the Self-Esteem and Achievement Motivation among the female NCC cadets of various colleges in Coimbatore. There is a no significant correlation between the two variables. Similarly, the ' $p$ ' value is 0.168 , which is $>/=0.05$, shows that there is no significant relationship between the two variables. Therefore, we can say that there is no significant increase in achievement motivation when the self-esteem is high and vice-versa.

Table 3 shows the mean, standard deviation and the t-test of the Self-Esteem and Achievement Motivation among the female non-NCC cadets. The mean and standard deviation of Self-Esteem is 24.94 and 18.04 respectively, which signifies a very high self-esteem for the group and the mean and standard deviation of Achievement Motivation is 18.04 and 4.12 respectively, which signifies an average level of achievement motivation for the group as a whole. 
Table 1 - Self-Esteem and Achievement Motivation among Female NCC Cadets

\begin{tabular}{|lcc|}
\hline Variables & Score & \\
& Mean & SD \\
\hline Self Esteem $(n=50)$ & 24.64 & 2.84 \\
Achievement motivation $(n=50)$ & 19.42 & 4.72 \\
\hline
\end{tabular}

Table 2 - Correlation between Self-Esteem and Achievement Motivation among Female NCC Cadets

\begin{tabular}{|ccc|}
\hline Variables & $\begin{array}{c}\text { Correlation of } \\
\text { co-efficient of ' } r \text { ' }\end{array}$ & $\begin{array}{c}\text { ' } \mathrm{p} \text { ' } \\
\text { value }\end{array}$ \\
\hline $\begin{array}{c}\text { Self Esteem }(\mathrm{n}=50) \\
\text { Achievement motivation }(\mathrm{n}=50)\end{array}$ & 0.198 & $0.168^{\mathrm{NS}}$ \\
\hline
\end{tabular}

NS - Not significant

Table 3 - Self-Esteem and Achievement Motivation among Female Non-NCC Cadets

\begin{tabular}{|lcl|}
\hline Variables & Score & \\
& Mean & SD \\
\hline Self Esteem $(\mathrm{n}=50)$ & 24.94 & 2.55 \\
Achievement motivation $(\mathrm{n}=50)$ & 18.04 & 4.12 \\
\hline
\end{tabular}

Table 4 shows the correlation and 'p' value between the Self-Esteem and Achievement Motivation among female non-NCC cadets. The correlation value is 0.095 which signifies that there is no correlation between the two variables and there is no relationship between the two variables. Similarly, the ' $p$ ' value is 0.514 , which is $>/=0.5$, shows that difference is not significant between the two variables. Therefore, it can be understood that there is no increase in achievement motivation with an increase in self-esteem.

Table 4 - Correlation between Self-Esteem and Achievement Motivation among Female Non-NCC Cadets

\begin{tabular}{|ccc|}
\hline Variables & $\begin{array}{c}\text { Correlation of } \\
\text { co-efficient of ' } \mathrm{r} \text { ' }\end{array}$ & $\begin{array}{c}\text { ' } \mathrm{p} \text { ' } \\
\text { value }\end{array}$ \\
\hline Self Esteem $(\mathrm{n}=50)$ & 0.095 & $0.514^{\mathrm{NS}}$ \\
Achievement motivation $(\mathrm{n}=50)$ & & \\
\hline
\end{tabular}

\section{NS - Not significant}

Table 5 - Difference between Self-Esteem among Female NCC and Non-NCC Cadets

\begin{tabular}{|cccc|}
\hline Variables & Score & 't 'value \\
& Mean & SD & \\
\hline NCC cadets $(\mathrm{n}=50)$ & 24.64 & 2.64 & $0.553^{\mathrm{NS}}$ \\
& & & \\
Non-NCC cadets $(\mathrm{n}=50)$ & 24.94 & 2.55 & \\
\hline
\end{tabular}

NS -Not significant

Indian Journal of Mental Health 2017;4(1) 
Table 5 shows the mean, standard deviation and t-test of the Self-Esteem among female NCC and nonNCC cadets. It was found that there was no significant difference between the groups. The non-NCC cadets were found to have slightly higher self-esteem as a group than the NCC cadets.

Table 6 shows the mean, standard deviation and t-test of the Achievement Motivation among the female NCC and non-NCC cadets. There is no significant difference in the Achievement Motivation of female NCC and non-NCC cadets. This may be because the NCC cadets often receive punishments and are reprimanded for even the smallest mistakes during their training. Though this helps them to improve their personality and achieve success in their tasks, it sometimes has a negative impact on their self-esteem. The non-NCC cadets who usually tend to participate in NSS activities get the opportunity to do direct help to the society and receive appreciation from those individuals. This boosts their self-esteem as they feel useful to the society. The non-NCC cadets are also allowed to do activities which pleases them and in which they are talented, whereas in NCC there are rules and regulations which need to be strictly adhered to.

Table 6 - Difference between Achievement Motivation among Female NCC and Non-NCC Cadets

\begin{tabular}{|cccc|}
\hline Variables & \multicolumn{2}{c}{ Score } & ' $\mathrm{t}$ 'value \\
& Mean & SD & \\
NCC cadets $(\mathrm{n}=50)$ & 19.42 & 4.72 & $1.653^{\mathrm{NS}}$ \\
Non-NCC cadets $(\mathrm{n}=50)$ & 18.04 & 4.12 & \\
\hline
\end{tabular}

NS -Not significant

The NCC cadets as a group have slightly higher Achievement Motivation in comparison to the non-NCC cadets. This may be due to the fact that the NCC cadets are being given more opportunities to achieve in camps and other activities such as firing, drill and written exams. Immediate results are provided to them and they are encouraged to develop a strong urge to improve by receiving individualized attention. Also, they are given appreciation and promotion based on their achievements. The non-NCC cadets do not receive as many opportunities and also are not able to receive individualized feedback or rewards as often as the NCC cadets.

Thus, the following are noted-

- There is no significant correlation between the Self-Esteem and Achievement Motivation among female NCC cadets. Therefore, the hypothesis 1 is accepted.

- There is no significant correlation between the Self-Esteem and Achievement Motivation among female non-NCC cadets. Therefore, the hypothesis 2 is accepted.

- There is no significant difference in the level of Self-Esteem between the female NCC and non-NCC cadets. Therefore, the hypothesis 3 is accepted.

- There is no significant difference in the level of Achievement Motivation between the female NCC and non-NCC cadets. Therefore, the hypothesis 4 is accepted.

\section{REFERENCES}

1. Weiner B. An attributional theory of achievement motivation and emotion. Psychol Rev 1985;92(4):548-73.

2. Wigfield A, Eccles JS. Expectancy-value theory of achievement motivation. Contemp Educ Psychol 2000;25(1):68-81.

3. Harackiewicz JM, Barron KE, Carter SM, Lehto AT, Elliot AJ. Predictors and consequences of achievement goals in the college classroom: Maintaining interest and making the grade. J Personal Soc Psychol 1997;73(6):1284-95.

4. Elliot AJ, McGregor HA. A $2 \times 2$ achievement goal framework. J Personal Soc Psychol 2001;80(3):501-19.

5. Elliot AJ. Approach and avoidance motivation and achievement goals. Educ Psychol 1999;34(3):169-89.

6. Brunstein JC, Maier GW. Implicit and self-attributed motives to achieve: Two separate but interacting needs. J Personal Soc Psychol 2005;89(2):205-22. 
7. Kehr HM. Integrating implicit motives, explicit motives, and perceived abilities: The compensatory model of work motivation and volition. Acad Manage Rev 2004;29(3):479-99.

8. Gawronski B, Bodenhausen GV. Associative and propositional processes in evaluation: an integrative review of implicit and explicit attitude change. Psychol Bull 2006;132(5):692-731.

9. Phillips JM, Gully SM. Role of goal orientation, ability, need for achievement, and locus of control in the self-efficacy and goal-setting process. J Appl Psychol 1997;82(5):792-802.

10. Brockner J. Self-esteem at work: Research, theory, and practice. Lexington Books/DC Heath and Com; 1988.

11. Branden N. The psychology of self-esteem: A new concept of man's psychological nature. Bantam Books; 1971.

12. Steinem G. Revolution from within: A book of self-esteem. Open Road Media; 2012.

13. Shastri VN. Achievement Motivation among Students. Ind J Research 2013;2(8):254-7.

14. Heydari, H., Madani, D. and Rostami, M. The Study of the relationships between achievement motiv, innovation, ambiguity tolerance, self-efficacy, self-esteem, and self-actualization, with the orientation of entrepreneurship in the Islamic Azad University of Khomein students. Proc Soc Behav Sci 2013;84(6):820-6.

15. Shekhar C, Devi R. Achievement motivation across gender and different academic majors. J Educ Dev Psychol 2012;2(2):105-10.

Acknowledgements - Nil

Source of Funding - Nil

Conflict of Interest - Nil 